\title{
Seasonal Influences on the Impulse Characteristics of Grounding Systems for Tropical Countries
}

\author{
Muhd Shahirad Reffin ${ }^{1}$, Abdul Wali Abdul Ali ${ }^{1}$, Normiza Mohamad Nor ${ }^{1, *}$, \\ Nurul Nadia Ahmad ${ }^{1}$, Syarifah Amanina Syed Abdullah ${ }^{1}$, Azwan Mahmud ${ }^{1}$ \\ and Farhan Hanaffi ${ }^{2}$ \\ 1 Faculty of Engineering, Multimedia University, 63100 Cyberjaya, Malaysia; \\ muhd_shahirad@yahoo.com (M.S.R.); walikdr17@gmail.com (A.W.A.A.); \\ nurulnadia.ahmad@mmu.edu.my (N.N.A.); synina@gmail.com (S.A.S.A.); \\ azwan.mahmud@mmu.edu.my (A.M.) \\ 2 Faculty of Electrical Engineering, Universiti Teknikal Malaysia Melaka, 76100 Durian Tunggal, Malaysia; \\ farhan@utem.edu.my \\ * Correspondence: normiza.nor@mmu.edu.my
}

Received: 12 March 2019; Accepted: 5 April 2019; Published: 8 April 2019

\begin{abstract}
One of the most important parameters of the performance of grounding systems is the soil resistivity. As generally known, the soil resistivity changes seasonally, hence the performance of grounding systems, at DC and under high impulse conditions. This paper presents the performance of grounding systems with two different configurations. Field experiments were set up to study the characteristics of the grounding systems seasonally at power frequency and under high impulse conditions. A review of field testing on practical grounding systems was also presented. It was found that the soil resistivity, RDC and impulse characteristics of grounding systems were improved over time, and the improvement was higher for electrodes that have more contact with the soils.
\end{abstract}

Keywords: grounding; grounding electrodes; high impulse conditions; seasonal; soil resistivity

\section{Introduction}

Grounding systems are necessary to discharge high fault currents to ground and ensure the safe operation of power systems at all time. It was reported in IEEE Standard 81 [1] that due to the soil settling process and compactness of the soil, the earth impedance of ground electrode decreases slightly over a year or more after installation, due to the soil settling process and improved compaction in the soil. A few research investigations have also been reported on the influence of soil resistivity on practical grounding systems at power frequency and high impulse current [2,3]. As generally known, soil composition, inhomogeneity, hydrological, geological process can vary seasonally, and some studies have analysed the seasonal influence on grounding systems in terms of resistance values at low voltage, and low currents by field experiments [4-7]. However, limited studies have been published on the seasonal influence on the performance of grounding systems under high impulse conditions. He et al. [8] observed the seasonal influence on grounding systems under high impulse conditions for two seasons: winter and summer. They observed that the soil resistivity at the top layer was stable, whereas a higher soil resistivity of the bottom layer was observed during winter than during summer [8]. This resulted in higher resistance at the power frequency in winter than during summer. When the impulse factor was measured as the ratio of $R_{\text {impulse }}$ to $R D C$, a close impulse factor was obtained for both seasons. However, the investigations on the impulse characteristics of grounding systems were completed for two seasons, and no continuous measurement was made in between the seasons. 
Further, the time period required for the checking and maintenance of grounding systems for both at power frequency and transient conditions has not been intensively studied or suggested. IEEE Standard 80:2013 [9] suggests the ground resistance be checked periodically after completion of construction, however, no specific time period is mentioned. Similarly, IEEE Standard 142: [10] and IEEE Standard 81 [1] state that power frequency tests should be conducted periodically, however, again no specific time period is suggested. Due to the lack of study on the seasonal performance of grounding systems and suggested time periods that can be found in literature, this paper therefore aims to address this shortfall.

In this study, field tests were used to investigate the characteristics of two practical grounding systems under high magnitude current surges throughout the year. Seasonal influences on the steady-state and impulse resistances were investigated, which represents the condition when the grounding systems were left over a period of time in real practice. These measurements allow a better understanding of the seasonal performances of grounding systems and provide information on how frequently grounding systems need to be checked and maintained after installation.

\section{Experimental Arrangement}

\subsection{Review of Field Testing and Measurements}

Different test arrangements may result in different and unreliable results when measuring the impulse characteristics of practical grounding systems. A review of field testing and measurement of impulse tests on grounding systems was firstly performed, to present various test set-ups and arrangements adopted in previously published works [2,8,11-27]. The study of soil behavior under impulse condition by means of field testing showed that the resistance decreased with increasing current [2,12-27]. It was noted from these studies [2,11-27] that the main concerns in the field measurements are the costs, logistics and time challenges. The guidelines were also found to be limited, due to the limited standards for field testing and measurements of grounding systems under high impulse conditions.

There are a few well established methods suggested in the standards on the measurements of earth resistance of earthing systems at low voltage and low frequency currents, namely the two-point method, three point method, ratio method, staged fault tests and fall-of-potential method [1,9,10]. However, it is now well accepted that soil characteristics under high magnitude impulse currents would become 'non-linear' and different than measured at low voltage and low frequency currents [2,8,11-27]. Due to the different characteristics of earthing systems under high impulse currents than when under low voltage, low frequency currents, there is a need to assess the practical earthing systems under high impulse conditions.

Field measurements undoubtedly can provide important results concerning the impulse characteristics of earthing systems since they represent the closest scenario to when high currents are practically discharged to grounding. With the improvement of impulse voltage/current generators which can be mobilized to the sites, impulse characterisations of earthing systems under high impulse conditions by field measurements have now become popular. Since then, a lot more studies have been directed towards impulse tests on earthing systems using field measurements. However, the measurement and testing methods found in these papers [11,13-27] differ from one another, which could be due to the lack of standards emphasising the required guidelines, as well as the great dependence on the available configurations and test site.

Since it is now well accepted that the impulse characteristics of earthing systems are different from those at low voltage low frequency currents, it is equally important to assess the performance of earthing systems under high impulse conditions. IEEE Standard 81 [1] provides some guidance and recommendations for measurements of earthing systems under high impulse conditions by field measurements, however they do not address it quantitatively, probably due to the little research work that has been carried out on grounding assessment under high impulse currents by field measurements. Other than the costs, logistics and time challenges in the field measurements, technical challenges are 
the main issues faced by researchers in performing field measurements of the impulse characteristics of earthing systems. This is due to the limited testing standards for field testing and measurements of earthing systems under high impulse conditions. Another technical challenge is due to the limited number of impulse generator manufacturers who are willing to tailor their designs to allow them to be mobilized to the field sites. So far, to the authors' knowledge, standards on impulse tests on practical earthing systems available in the literature are limited.

\subsubsection{Distance of Remote Earth from the Electrode under Tests}

In IEEE Std 81 [1], brief guidelines are provided for measurements at field sites using a mobile impulse generator. The work presented in IEEE Std 81 [1] is based on the tests conducted at the Georgia Institute of Technology. It was suggested in IEEE Standard 81 [1] to have the same leads and reference ground arrangement as that used for low-frequency Fall-of-Potential (FOP) tests. Figure 1 shows the test arrangement for the experimental test set-up of earthing systems under high impulse conditions. The distance of the electrode under test to the earth probe is $62 \%$ of the distance between the electrode under test to the remote earth. As for the ground mat, it was recommended in IEEE Std. 80 [9] that the dimensions of the electrode under test to the remote earth be extended by 3 to 4 times the diagonal dimensions of the ground mat. However, the IEEE standard guidelines are brief, and many other authors [11,13-22] have adopted other test set-up arrangements in their measurements, where all these distances were not as specific as those highlighted in the IEEE Standard [1].

\subsubsection{Impulse Generator}

As for the mobile impulse generator, no generally accepted standard has been presented so far. Some studies [18] used laboratory facilities, without any special design changes to the impulse generator for the testing of earthing systems by field measurements. On the other hand, some studies $[13,15,16,19]$ have used impulse generators purposely built for their tests of earthing systems under high impulse conditions by field measurements. Marimoto et al. [16] have exclusively developed a weatherproof mobile impulse voltage generator in an effort to test the grounding systems of power substations.

No detailed information has been published in the standards on the specific methods, procedures and precautions of the measurements for testing the earthing systems at field sites. It was briefly highlighted in [1] that the current and voltage leads should be isolated from earth to avoid any interference, which can be done by hanging the leads over polyvinyl chloride (PVC) conduits. Different methods of hanging these leads to isolate the earth have also been found in some other studies $[16,19]$. However, other studies have not mentioned any consideration of the isolation of the leads [17-21]. This shows that there is a need to clarify the proper measurement methods.

\subsubsection{Remote Earth/Auxiliary Earth}

Another important parameter that needs to be considered in the experimental arrangement forthe testing of earthing systems by field measurements is the auxiliary ground, which is needed to carry the return current to the impulse generator via the ground under tests. So far, to the authors' knowledge, no specific standard has discussed the design requirements of this auxiliary ground.

Some authors have constructed auxiliary grounds around the electrode under tests. In this arrangement, a bigger remote earth size is expected since it is installed around the electrode under test. Thus, the earth resistance values of the ring electrode may be expected to have lower earth resistance values than the electrode under test. References $[20,21]$ have used a remote earth installed around the electrode under tests. A few clarifications are needed when having the remote earth around the electrode under tests such as the appropriate radius of remote earth that should be constructed around the electrode under tests.

On the other hand, some authors $[12,13,15-19]$ used separate earthing systems, which are constructed away from the electrode under tests as the auxiliary ground. It is stated in IEEE Standard 80 [1] that the earth resistance of remote earth should be lower than that the electrode under tests. 
However, many times the steady state earth resistance values of the remote earth have not been mentioned or addressed by some authors. Though the remote earth constructions look bigger in the published work [12,13,15-19], the earth resistance values of the remote earth were not specifically mentioned in the papers. Yunus et. al. [17] studied the effects of earth resistance values of remote earths on the electrodes under test for when the remote earth was placed away from the electrode under test. Some significant observations were that the results were found to be different than the findings in most literatures, with higher earth resistance values of the remote earth than that the electrode under tests [17], and where the impulse earth resistance value was found to be higher than that measured at low voltage and low frequency currents (DC earth resistance value) when higher remote earth resistance values were used. They also found that the earth resistance values of electrodes under test increased with increasing currents in the higher earth resistance values of the remote earth [17].

Further, Abdullah et al. [22] compared both arrangements (remote earth around the electrode under test and remote earth placed at some distance away from the electrode under tests). They [22] found close agreement between the results of these two arrangements. This shows that both test arrangements are acceptable, as long as the condition that the earth resistance value of the remote earth be smaller than that of the electrode under testing is met.

\subsubsection{Placement of Current Transducer}

Other concerns for the field measurements and testing of the earthing systems under high impulse conditions are the placement of current transducers during the field measurements. In some published papers [23-26], the experimental arrangement was not shown at all, though some parameters of the generators and test circuit are described. Due to the different possible arrangements of the remote earth, surrounding the electrode under tests and away from the electrode under test, as highlighted in Section 3, the placement of the current transducer (CT) would expectedly be different too.

Here, the placement of the CT for the remote earth placed at a distance away from the electrode under test is discussed first. In IEEE Standard 81 [1], the current transducer was placed at the electrode under test, at the same point where the cable of voltage divider was also connected. Some studies $[15,21,24,25,28]$ also positioned the CT in series to the electrode under tests.

On the other hand, for the arrangement where the remote earth is placed at some distance away from the electrode under tests, Chen and Chowdhuri [27] measured the current at the remote earth, and not in series to the electrode under tests. So far, to the authors' knowledge, such an arrangement was only found in their paper [27]. As for other papers, i.e., [13,15,16], they did not clearly show the CT placement, though there were some current measurements. Due to a lack of test set-up arrangements, the authors feel that there is a need for a proper standard for impulse tests on earthing systems by field measurements. As for other kinds of arrangement where the remote earth is installed around the electrode under tests, the CT is more commonly placed at the remote earth $[12,20,22]$.

\subsection{Test Set up for This Study}

In the investigation described in this paper, a mobile impulse generator which is capable of generating high voltages up to $300 \mathrm{kV}$ and high impulse currents up to $10 \mathrm{kA}$ was used (see Figure 1). The impulse generator was powered by a diesel generator. Current measurements were achieved with a current transformer of sensitivity of $0.01 \mathrm{~V} / \mathrm{A}$ and with an attenuation of the probe of $\times 10$. A resistive divider with a ratio of 3890:1 was used for voltage measurements. Two commercially available digital storage oscilloscopes (DSOs), powered by batteries, were used to capture the voltage and current signals separately. In order to avoid any interferences and flashover in the circuit, all equipment and leads were placed above ground. For the diesel generator and impulse generator, an epoxy was used as a frame to separate them from the ground. For the DSOs, the batteries are placed on an insulation table, made of epoxy. All the leads and mesh cables were isolated from the ground by hanging the leads on epoxy insulation rods. Figure 2 shows the experimental arrangement of the impulse tests of grounding systems under high impulse conditions. 


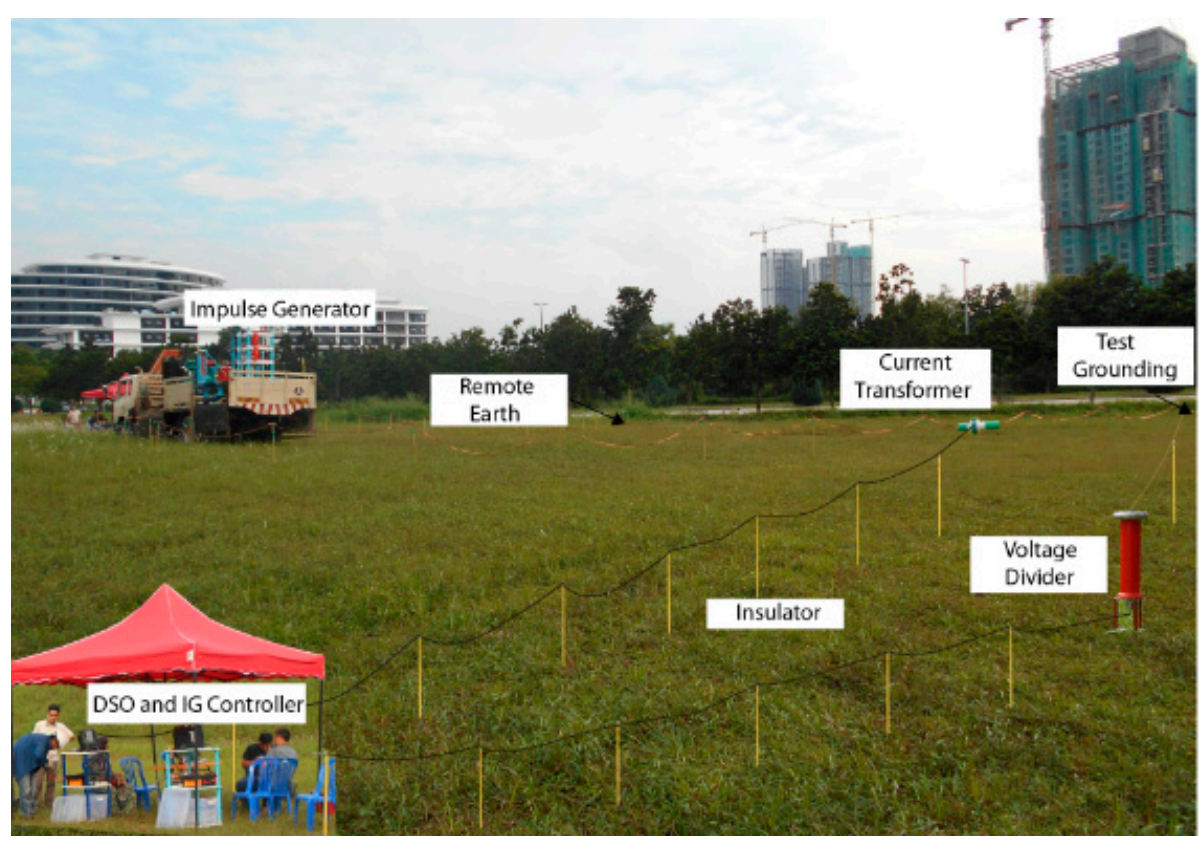

Figure 1. Equipment used for field measurements.

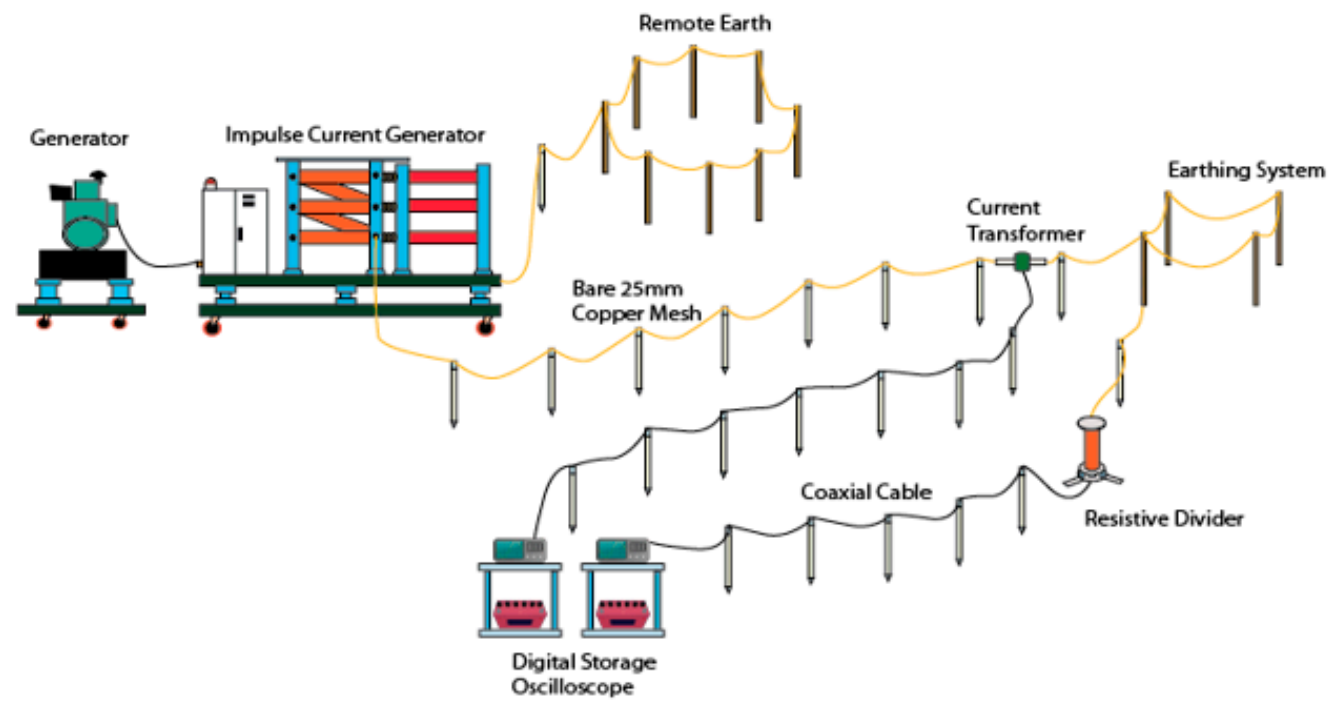

Figure 2. Test set-up for field measurements.

\subsection{Electrodes under Tests}

In this study, two configurations were adopted: a grounding device with spike rods (configuration 1) and one with four rod electrodes (configuration 2), shown in Figures 3 and 4, respectively. Configuration 2 represents a conventional electrode, where the design does not emphasize any enhancement of the ionization process. Configuration 1 was developed based on the evidence from the work by Petropolous [28] that when spikes or needles were attached to the spherical electrode, lower impulse resistance values were noted for the same voltage due to the higher field intensities at the spikes. This indicates the effectiveness of the earth electrodes with spikes as compared to electrodes without spikes. In this paper, a new grounding electrode with spike rods is introduced. By having spike rods at the electrodes, a high electric field intensity will be concentrated at the spikes, which encourages soil ionisation and breakdown processes to take place, hence allowing more current to be discharged to the ground. This will result in a more effective grounding system. For this reason, and to provide more contact between the electrodes and surrounding soil, a grounding device with spike rods (consisting of two rods (inner shaft (120) and outer shaft electrodes (110)) was adopted. The grounding 
device with spike rods is $1.5 \mathrm{~m}$ in length. The diameter of the inner rod is $3 \mathrm{~cm}$, and outer rod is $5 \mathrm{~cm}$, with a gap between inner and outer rods of $1 \mathrm{~cm}$. There are five spikes (123), each one of $20 \mathrm{~cm}$ length. During the installation, the spike rods (123) are kept closed from the surface. For the installation, due to its large diameter, a pre-bore with a diameter of $4 \mathrm{~cm}$ was firstly performed using an auger. Upon completing a pre-bore hole with a depth of $1.5 \mathrm{~m}$, the grounding device with spike rods (100) is positioned into the hole, in a generally vertical configuration, with all the spike rods (123) concealed and protected from damage within the shaft. The outer shaft (110) is subjected to impact force while it is driven through hammering into the ground. During driving, the top end is protected by a dolly or capping to protect the top end of the shaft against any damage from driving or hammering the electrodes. Once the grounding device with spike rods (100) reached the required distance, $1.5 \mathrm{~m}$, the inner shaft (120) was turned using the provided winch (121) in such a way that the grounding spike rods (123) protruded out and pierced into the soil mass. An indication that all the spike rods (123) protrude out is when the winch stops, and is not able to turn the inner shaft (120) anymore. Another type of ground electrode used in this study consists of four ground rod electrodes, with each rod of $20 \mathrm{~mm}$ diameter, and a depth of $1.5 \mathrm{~m}$. Copper mesh of $25 \mathrm{~mm}$ width and thickness of $2 \mathrm{~mm}$ was used to connect the rod electrode at all four points, as shown in Figure 4.

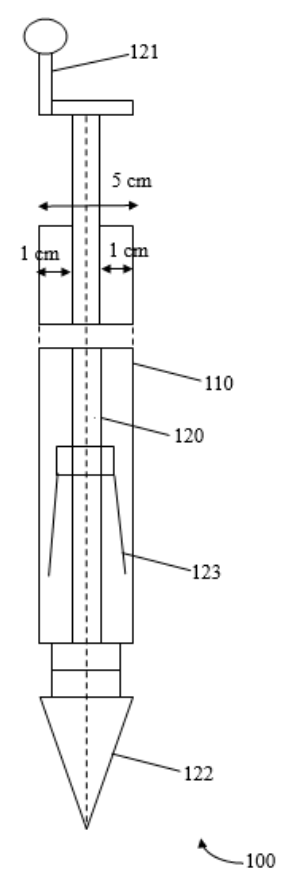

Figure 3. Configuration 1, consists of a grounding device with spike rods.

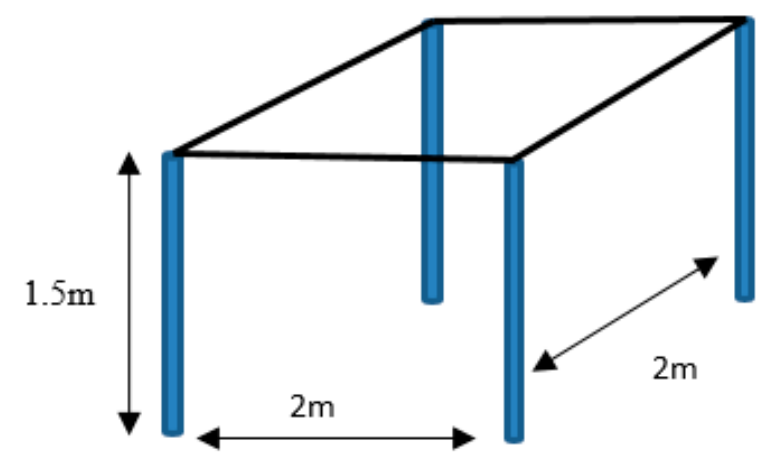

Figure 4. Configuration 2 for the tests, consisting of a $2 \mathrm{~m} \times 2 \mathrm{~m}$ grounding grid. 
In this study, the Finite Element Method (FEM) was utilized to obtain the voltage profiles for both configurations. Figures 5 and 6 show the point of electric profile is taken for configurations 1 and 2 , respectively. The soil resistivity was taken at the beginning of the tests using a Wenner Method, which was computed as a two-layer medium model, using a Current Distribution, Electromagnetic Fields, Grounding and Soil Structure Analysis (CDEGS) software. It was found that the resistivity at the top layer is $119.5 \Omega \mathrm{m}$ with a depth of $7.18 \mathrm{~m}$, and the bottom of a two-layered soil is $391 \Omega \mathrm{m}$, with an infinite depth. Both configurations were injected at $5 \mathrm{kA}$. The corresponding trends of the electric field for configurations 1 and 2 are shown in Figures 7 and 8, respectively. As can be noted, the shapes of the electric fields for both configurations are different when a similar soil resistivity layer was used. A higher and more non-uniform electric field was noted for configuration 1, where the maximum surface potential is $820 \mathrm{MV}$ (see Figure 7). For the case of configuration 2, the potential is rather uniform, with $650 \mathrm{MV}$ at the rod, and $180 \mathrm{MV}$ at the copper strips (see Figure 8). The FEM simulation indicates that configuration 1 is preferred, since it can increase the electric field significantly, and has non-uniform electric field, thus reducing the earth resistance value more significantly under transient conditions, compared to configuration 2.

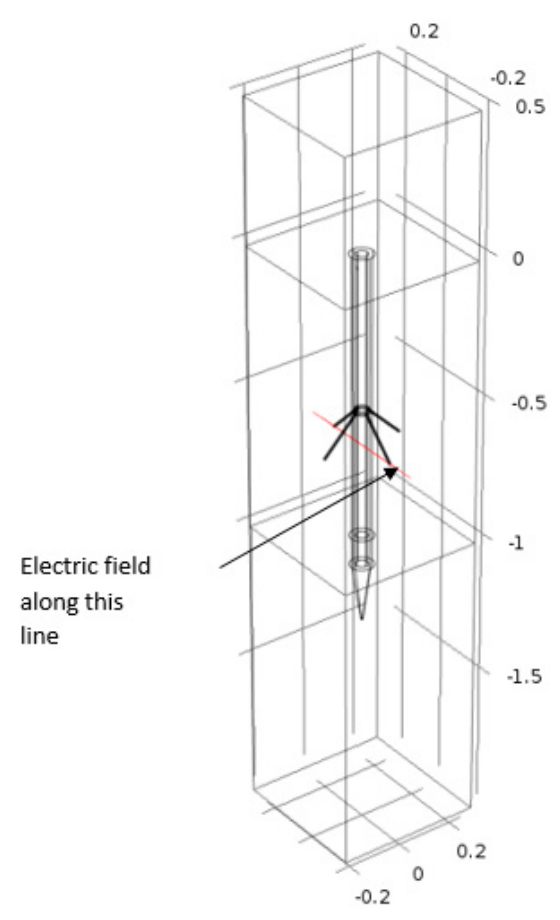

Figure 5. Electric profile is taken along the spike rods.

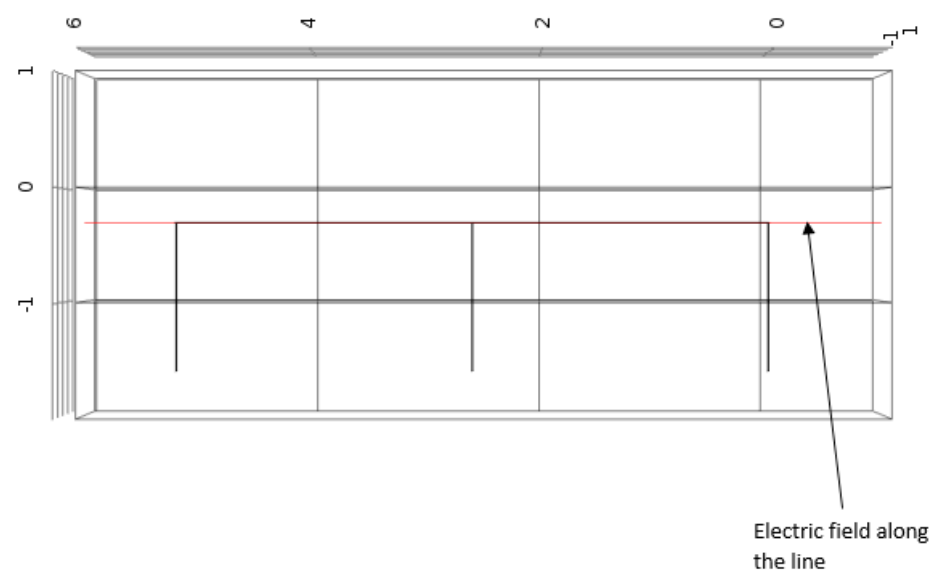

Figure 6. Electric profile taken along the conventional rods. 
Line Graph: Electric field norm (V/m)

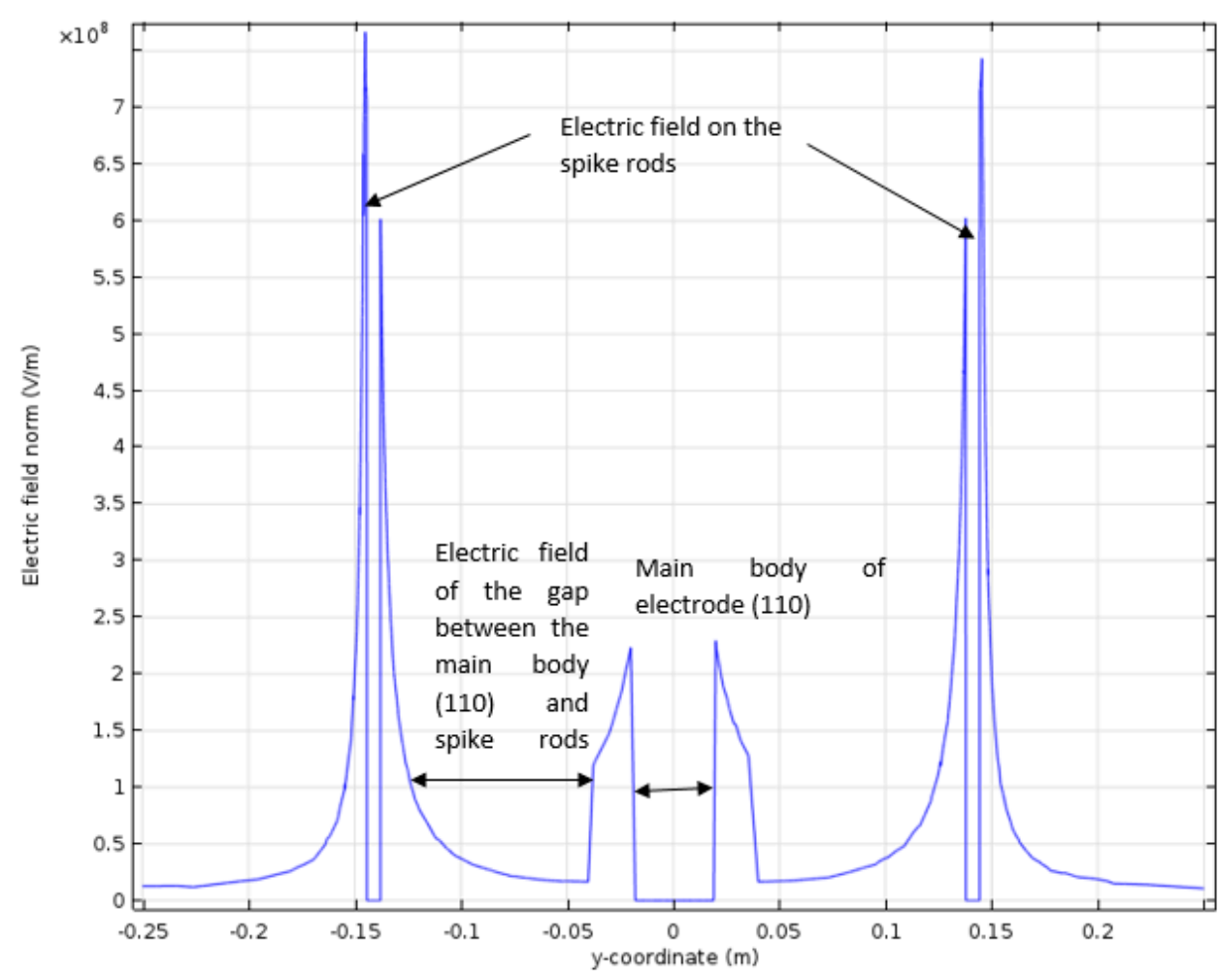

Figure 7. Electric field along the spike rods.

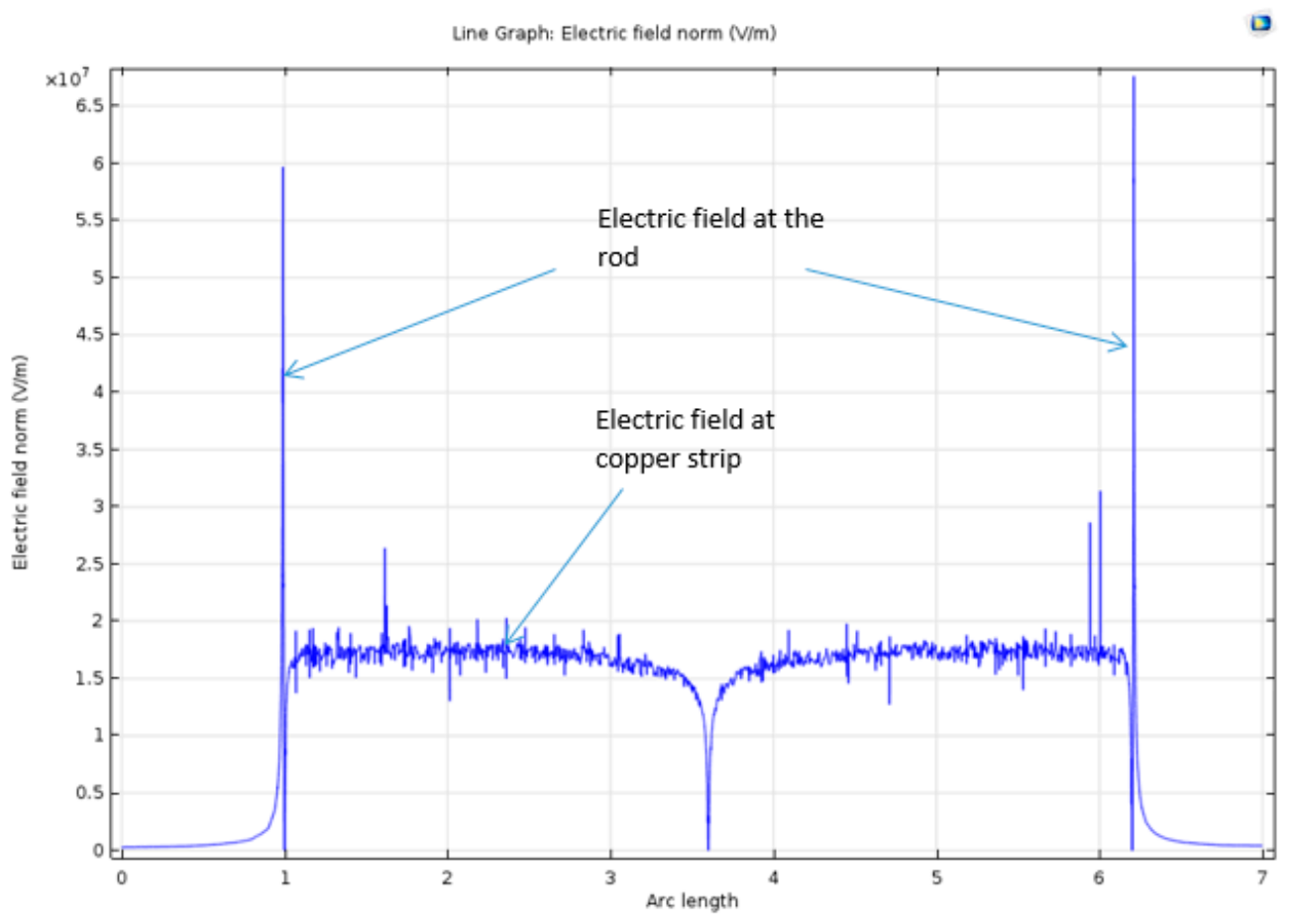

Figure 8. Electric field along the conventional rods.

\subsection{Auxillary or Remote Electrodes}

A larger size of auxillary or remote earth grounding system was used, so that a lower earth resistance value was achieved, in comparison to the test electrodes, presented earlier in Section 2.2. In this study, the remote earth was installed $50 \mathrm{~m}$ away from the electrode under tests. Figure 9 shows 
the remote earth used in this study, which consists of a $20 \mathrm{~m} \times 30 \mathrm{~m}$ grounding grid. The spacing between copper strips is $5 \mathrm{~m}$ apart for the $20 \mathrm{~m}$ side and $15 \mathrm{~m}$ apart for the $30 \mathrm{~m}$ side. Hard copper strips of $30 \mathrm{~mm}$ width and $2 \mathrm{~mm}$ thick were used, which were buried $300 \mathrm{~mm}$ below the earth's surface, and welded exothermically to 12-rod electrodes, where each one is $20 \mathrm{~mm}$ in diameter, and $1.8 \mathrm{~m}$ long. Using a Fall-of-Potential (FOP) method, the earth resistance values of the remote earth were measured, and found to range between $8.5 \Omega$ to $10 \Omega$ throughout the year, which is always lower than the electrodes under tests.

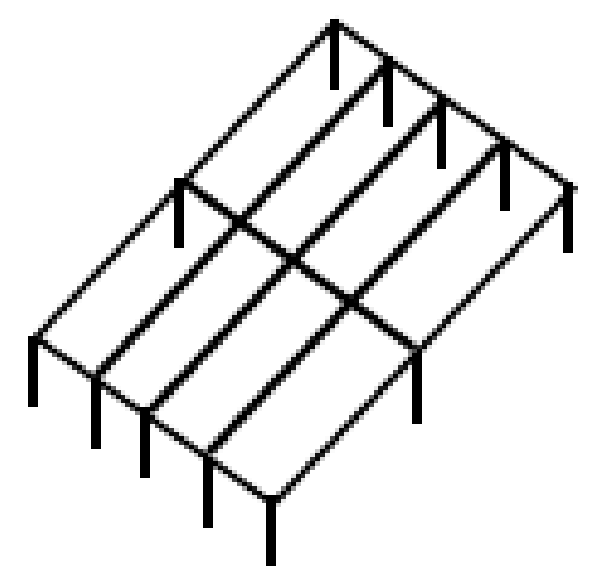

Figure 9. A $20 \mathrm{~m} \times 30 \mathrm{~m}$ remote earth mesh.

\section{Results and Analysis}

Using the Wenner method, the soil resistivity was measured in March 2018 and March 2019 to see variations in soil profile over the year. Configurations 1 and 2 are $30 \mathrm{~m}$ apart. The soil resistivity was measured at the site over $150 \mathrm{~m}$-long lines within the test site, and these configurations were installed within this $150 \mathrm{~m}$-long line. The results were then modeled into 2-layer soil model using Current Distribution, Electromagnetic Interference, Grounding and Soil Structure Analysis (CDEGS), which results are summarised in Table 1. As can be seen, the soil resistivity slightly varied over the year, with the height of the first layer also being reduced after a year. FOP, as outlined in IEEE Standard 81 [1] was applied to measure the DC and low-current resistances of configurations 1 and 2 throughout the year, which are shown in Table 2. The resistances of both configurations were found to reduce after the installation, where a higher reduction was seen for configuration 1 , with a decrease by more than $20 \%$ throughout the year. This could be due the presence of five spike rods, which provide more contact within the soil, as compared to configuration 2. It was also noted that for the measurement in September 2018, high RDC values were noted for both configurations, with respect to any other months. It was experienced by the authors that during the measurement, the weather was hotter than the rest of the months.

Table 1. Soil resistivity profile.

\begin{tabular}{cccc}
\hline Month of Measurement & $\begin{array}{c}\text { Soil Resistivity of } \\
\text { Layer } \mathbf{1}, \boldsymbol{\varrho}_{\mathbf{1}}(\mathbf{\Omega})\end{array}$ & $\begin{array}{c}\text { Soil Resistivity of } \\
\text { Layer } \mathbf{2}, \boldsymbol{\varrho}_{\mathbf{2}}(\boldsymbol{\Omega} \mathbf{m})\end{array}$ & Height of Layer $\mathbf{1}(\mathbf{m})$ \\
\hline March 2018 & 119.5 & 391.0 & 7.2 \\
\hline March 2019 & 111.4 & 454.2 & 5.2 \\
\hline
\end{tabular}

Right after RDC measurements, impulse tests were performed on both test electrode configurations on the same day. Impulse currents and the corresponding voltages were measured and shown in Figures 10 and 11 for configuration 1, at charging voltage of $30 \mathrm{kV}$ and $210 \mathrm{kV}$, respectively, for test no. 1 . As can be seen in the figures, faster times to discharge to zero for both voltage and current traces was seen at higher voltage magnitudes. Similar voltage and current traces were seen for configuration 2 , and for other test 
nos., where faster times to discharge to zero for both voltage and current traces at higher currents were observed. The time to discharge to zero for voltage and current was plotted against the applied voltage for all the tests, the time to discharge to zero decreased with applied voltage, as shown in Figures 12 and 13 for configuration 1 and 2, respectively. Both configurations were found to have the slowest time to discharge to zero for test no.4, which has high RDC. Both configurations with the lowest RDC (in Dec. 2018) were found to have the fastest discharge time to zero, indicating a good conductivity of the grounding systems. Time to discharge to zero was also found to be higher for configuration 1, in comparison to configuration 2 (see Figures 14 and 15) for test no. 1 to 3, and no. 3-7 respectively). The results also indicated that the lower the RDC, the faster the time for current and voltage to discharge to zero.

Table 2. Measured resistance of electrodes at power frequency, low-current tests.

\begin{tabular}{|c|c|c|c|c|c|}
\hline \multirow[b]{2}{*}{ Test No. } & \multirow[b]{2}{*}{ Date of Measurement } & \multicolumn{4}{|c|}{ DC Resistance, RDC $(\Omega)$} \\
\hline & & Conf. 1 & $\begin{array}{l}\text { Percentage Difference from } \\
\text { the First Reading (\%) }\end{array}$ & Conf. 2 & $\begin{array}{l}\text { Percentage Difference from } \\
\text { the First Reading (\%) }\end{array}$ \\
\hline 1 & $21 / 03 / 2018$ & 91 & 0 & 60.9 & 0 \\
\hline 2 & $07 / 05 / 2018$ & 69.1 & 24.1 & 55.2 & 9.36 \\
\hline 3 & $02 / 08 / 2018$ & 69.7 & 23.4 & 57.5 & 5.58 \\
\hline 4 & 03/09/2018 & 84.2 & 7.25 & 80.3 & -31.9 \\
\hline 5 & $17 / 10 / 2018$ & 71.9 & 20.99 & 57.1 & 6.24 \\
\hline 6 & $21 / 11 / 2018$ & 70.7 & 22.3 & 55.9 & 8.2 \\
\hline 7 & $17 / 12 / 2018$ & 70.1 & 23 & 57.1 & 6.24 \\
\hline 8 & $25 / 2 / 2019$ & 69 & 24.2 & 55.5 & 8.9 \\
\hline
\end{tabular}

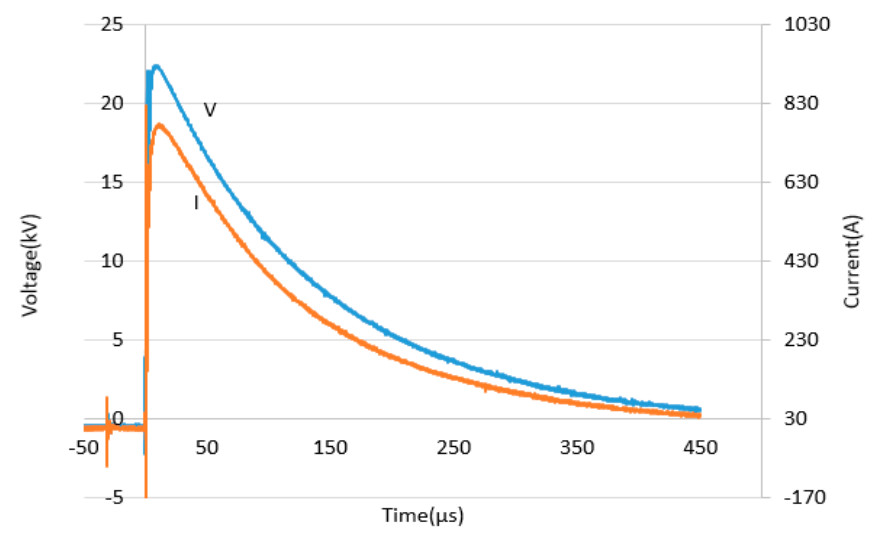

Figure 10. Voltage and current traces for configuration 1 at a charging voltage of $30 \mathrm{kV}$.

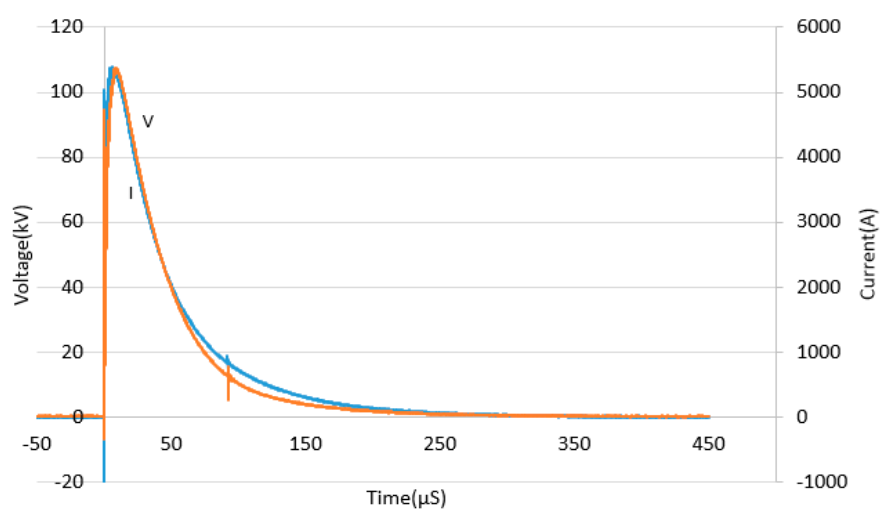

Figure 11. Voltage and current traces for configuration 1 at a charging voltage of $210 \mathrm{kV}$. 
Impulse resistance values were measured as the ratio of the voltage at current peak to the current peak, and plotted versus the peak current, as shown in Figures 16 and 17 for configurations 1 and 2, respectively. The resistance values obtained from these tests were found to decrease with current magnitude, indicating the effect of impulse currents on the characteristics of test electrodes for configurations 1 and 2. It was noted that the impulse resistance are lower a few months after installation, showing improvement in the grounding systems for both configurations. In order to determine the effectiveness of the test electrodes in comparison to its RDC, the percentage of reduction of impulse resistance from its corresponding RDC was measured as (1), where the $R_{\text {impulse }}$ was taken as the average impulse resistance measured from varying the charging voltage of $30 \mathrm{kV}$ until $210 \mathrm{kV}$ :

$$
\text { Percentage of resistance reduction }=\left(\frac{R_{D C}-R_{\text {impulse }}}{R_{D C}}\right) \times 100 \%
$$

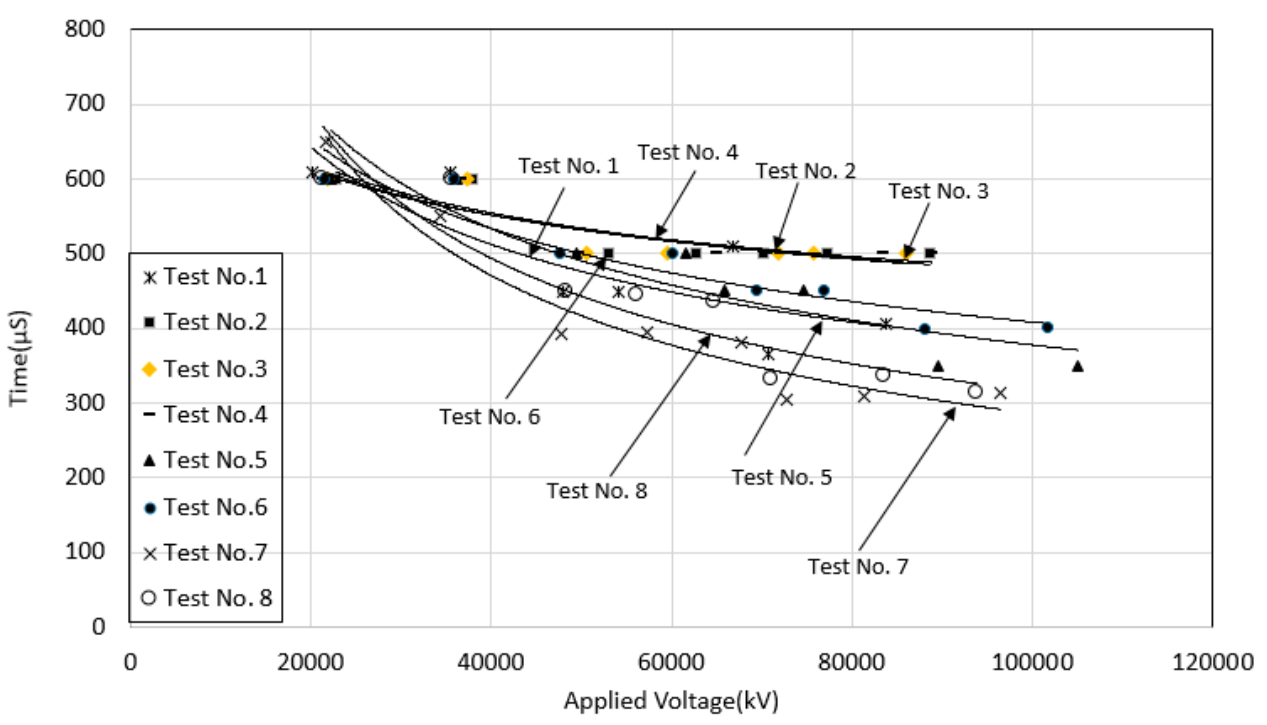

Figure 12. Time to discharge to zero for voltage and current traces for configuration 1 throughout the year.

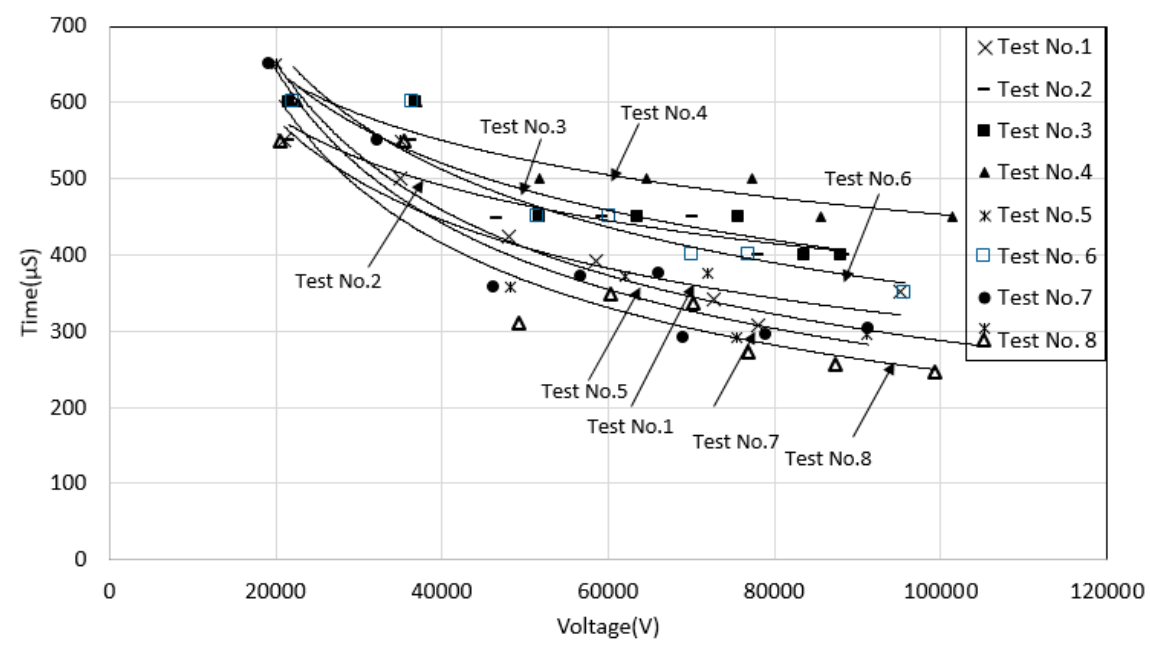

Figure 13. Time to discharge to zero for voltage and current traces for configuration 2 throughout the year. 


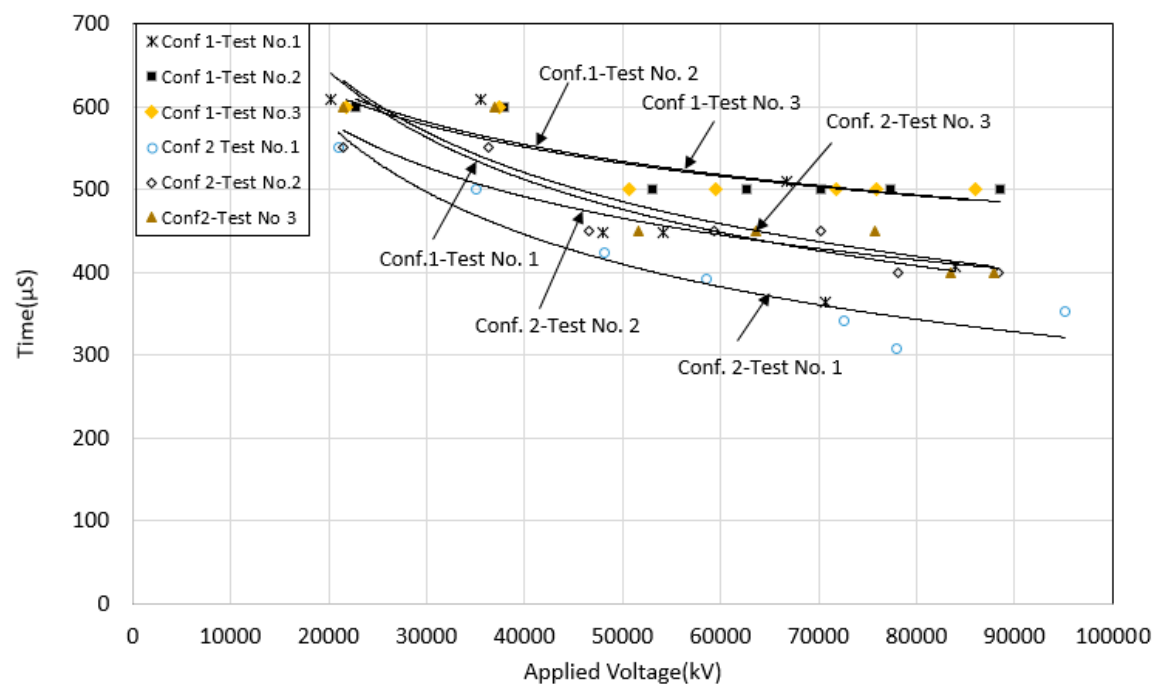

Figure 14. Time to discharge to zero for voltage and current traces for configuration 1 and 2 for tests no. 1 to 3 .

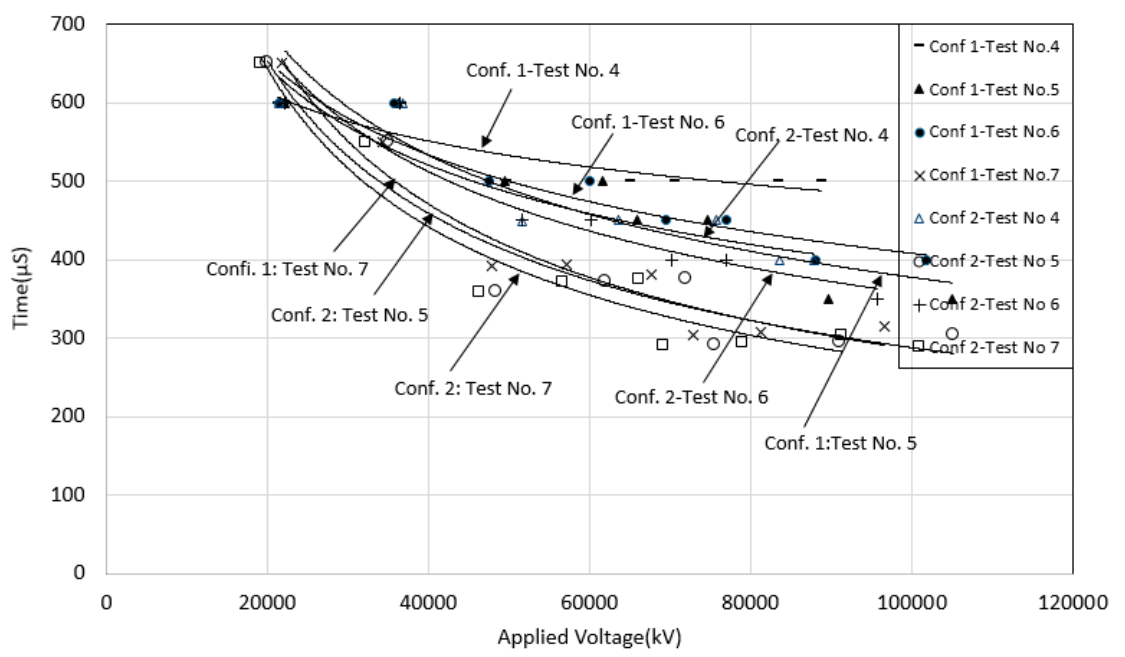

Figure 15. Time to discharge to zero for voltage and current traces for configuration 1 and 2 for tests no. 4 to 7 .

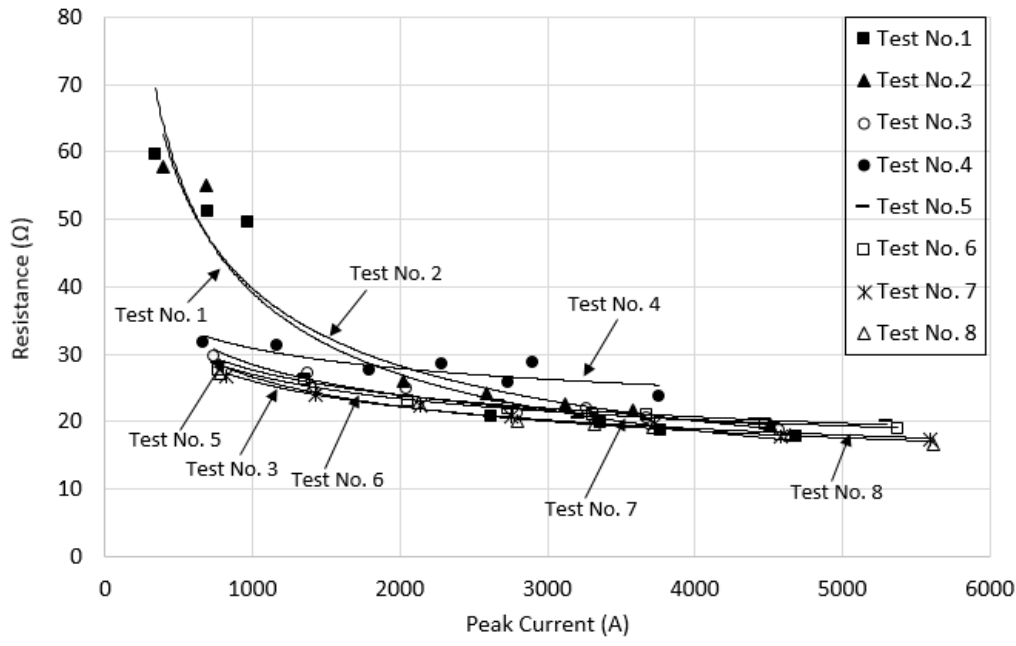

Figure 16. Impulse resistance vs. peak current for configuration 1 throughout the year. 


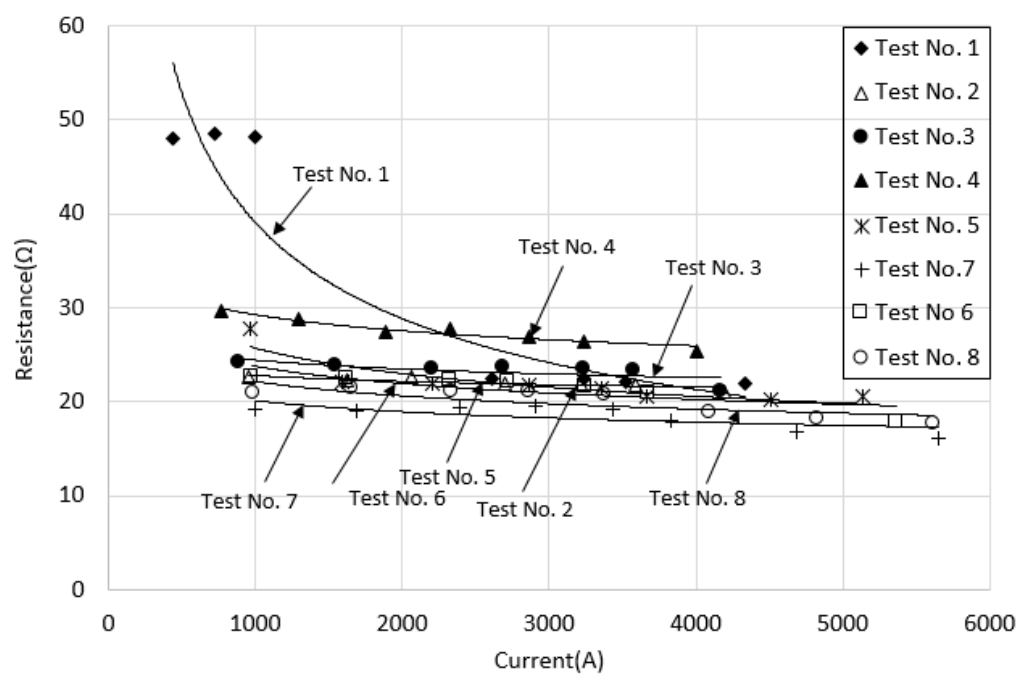

Figure 17. Impulse resistance vs. peak current for configuration 2 throughout the year.

Table 3 summarises the impulse factor for both configurations, measured throughout the year. As can be seen from the table, percentage of resistance reduction is higher for configuration 1, in comparison to configuration 2. A higher percentage of resistance reduction for configuration 1 after a months of installation was also noted, showing the effectiveness of the earth electrode design with spike rods.

Table 3. Percentage of impulse resistance reduction from RDC throughout the year.

\begin{tabular}{ccccccc}
\hline \multirow{2}{*}{ Test No. } & \multicolumn{2}{c}{ Configuration $\mathbf{1}$} & \multicolumn{2}{c}{ Configuration 2 } \\
\cline { 2 - 7 } & $\mathbf{R}_{\mathbf{D C}}$ & Average $\mathbf{R}_{\text {impulse }}(\boldsymbol{\Omega})$ & $\begin{array}{c}\text { Resistance Reduction } \\
\text { from } \mathbf{R}_{\mathbf{D C}}(\mathbf{\%})\end{array}$ & $\mathbf{R}_{\mathbf{D C}}$ & Average $\mathbf{R}_{\text {impulse }}(\boldsymbol{\Omega})$ & $\begin{array}{c}\text { Resistance Reduction } \\
\text { from } \mathbf{R}_{\mathbf{D C}}(\mathbf{\%})\end{array}$ \\
\hline 1 & 91 & 33.94 & 62.7 & 60.9 & 33.4 & 45.1 \\
\hline 2 & 69.1 & 32.4 & 53.1 & 55.2 & 22.0 & 60.1 \\
\hline 3 & 69.7 & 23.5 & 66.3 & 57.5 & 23.3 & 59.5 \\
\hline 4 & 84.2 & 28.2 & 66.5 & 80.3 & 27.6 & 65.6 \\
\hline 5 & 71.9 & 23 & 68 & 57.1 & 22.2 & 61.1 \\
\hline 7 & 70.7 & 22.5 & 68.2 & 55.9 & 21.4 & 61.7 \\
\hline
\end{tabular}

\section{Conclusions}

Power frequency and impulse tests by field measurements on a grounding device with spike rods and a small grid were performed throughout the year. It was found that under high impulse conditions, the RDC of both configurations became lower after months of installation. The percentage of reduction of RDC from the first installation was found to be more pronounced for configuration 1 than configuration 2, suggesting the effectiveness of the new grounding electrode with configuration 1. This could be due to the spike rods in the grounding electrode, providing more and better contact of the electrodes with the soil, hence reducing the RDC. The characteristics of both configurations were also investigated under high impulse currents. The percentage of earth resistance reduction of $R_{\text {impulse }}$ from its RDC was found to be higher for configuration 1. In addition, a higher percentage of earth resistance reduction was exhibited for configuration 1 after months of installation, indicating an improvement in the grounding systems for electrodes with spikes. The results from the study provide an important guideline for power engineers concerning the time period that needs to be considered for maintenance of grounding systems, where it is desirable to perform the maintenance of grounding systems after one year of installation. The results indicate that it may be desirable to consider using electrode rods with spike rods, so that earth resistance values can be reduced under transient conditions. This scenario 
gives a more effective grounding system, which enhances the ionisation process and increases the dissipating current.

Author Contributions: M.S.R., A.W.A.A., N.M.N., S.A.S.A. and N.N.A. involved in setting up the experiment, M.S.R. and A.W.A.A. sorted out the data, M.S.R. and A.W.A.A. prepared the draft and N.M.N. helped with validation of analysis. A.M., N.M.N. and N.N.A. helped in securing funding. F.H. helped with the FEM simulation.

Funding: This research was funded by TELEKOM MALAYSIA RESEARCH AND DEVELOPMENT (TMR\&D), grant number MMUE170005, MMUE180008 and MMUE180027.

Conflicts of Interest: The authors declare no conflict of interest.

\section{Subscripts and Abbreviations}

DC Direct current

$R_{\text {impulse }} \quad$ Resistance values measured under impulse condition

RDC Resistance values measured at low voltage, low frequency currents

DSO Digital Storage Oscilloscope

FEM Finite Element Method

CDEGS Current Distribution, Electromagnetic Fields, Grounding and Soil Structure Analysis

FOP Fall-of-Potential

\section{References}

1. ANSI/IEEE Std 81-2012. IEEE Guide for Measuring Earth Resistivity, Ground Impedance, and Earth Surface Potentials of a Ground System; IEEE: Piscataway, NJ, USA, 2012.

2. Reffin, M.S.; Nor, N.M.; Ahmad, N.N.; Abdullah, S.A. Performance of Practical Grounding Systems under High Impulse Conditions. Energies 2018, 11, 3187. [CrossRef]

3. Tu, Y.; He, J.; Zeng, R. Lightning Impulse Performances of Grounding Devices Covered with Low-Resistivity Materials. IEEE Trans. Power Deliv. 2006, 21, 1701-1706. [CrossRef]

4. Gustafson, R.J.; Pursley, R.; Albertson, V.D. Seasonal Grounding Resistance Variation on Distribution Systems. IEEE Trans. Power Deliv. 1990, 5, 1013-1018. [CrossRef]

5. Abdullah, N.; Marican, A.; Osman, M.; Abdul, N. Rahman Case Study on Impact of Seasonal Variations of Soil Resistivities on Substation Grounding Systems Safety in Tropical Country. In Proceedings of the 7th Asia-Pacific International Conference on Lightning, Chengdu, China, 1-4 November 2011; pp. 150-154.

6. Gonos, I.; Gonos, I.F.; Moronis, A.X.; Stathopulos, I.A. Variation of Soil Resistivity and Ground Resistance during the Year. In Proceedings of the 28th International Conference on Lightning Protection (ICLP), Kanazawa, Japan, 17-21 September 2006; pp. 740-744.

7. Androvitsaneas, V.P.; Gonos, I.; Stathopulos, I.A. Performance of Ground Enhancing Compounds during the Year. In Proceedings of the 34th International Conference on Lightning Protection (ICLP), Rzeszow, Poland, 2-7 September 2018; pp. 1-5.

8. He, J.; Wu, J.; Zhang, B.; Yu, S. Field Testing for Observation of Seasonal Influence on Grounding Device at Impulse Condition. In Proceedings of the Asia-Pacific Symposium on Electromagnetic Compatibility, Singapore, 21-24 May 2012; pp. 445-448.

9. ANSI/IEEE Std 80-2013: IEEE Guide for Safety in AC Substation Grounding; IEEE: Piscataway, NJ, USA, 2013.

10. IEEE 142-2007: IEEE Recommended Practice for Grounding of Industrial and Commercial Power Systems; IEEE: Piscataway, NJ, USA, 2007.

11. Bellaschi, P.L. Impulse and 60-Cycle Characteristics of Driven Grounds. IEE Trans. Power Appar. Syst. 1941, 60, 123-128.

12. Kosztaluk, R.; Loboda, M.; Mukhedkar, D. Experimental Study of Transient Ground Impedances. IEEE Trans. Power Appar. Syst. 1981, 100, 4653-4660. [CrossRef]

13. Sekioka, S.; Hara, T.; Ametani, A. Development of a Nonlinear Model of a Concrete Pole Grounding Resistance. In Proceedings of the International Conference on Power Systems Transients, Lisbon, Portugal, 3-7 September 1995; pp. 463-468.

14. Dick, W.K.; Holliday, H.R. Impulse and Alternating Current Tests on Grounding Electrodes in Soil Environment. IEEE Trans. Power Appar. Syst. 1978, PAS-97, 102-108. [CrossRef] 
15. Sekioka, S.; Sonoda, T.; Ametani, A. Experimental Study of Current Dependent Grounding Resistance of Rod Electrode. IEEE Trans. Power Deliv. 2005, 20, 1569-1576. [CrossRef]

16. Morimoto, A.; Hayashida, H.; Sekioka, S.; Isokawa, M.; Hiyama, T.; Mori, H. Development of Weatherproof Mobile Impulse Voltage Generator and Its Application to Experiments on Nonlinearity of Grounding Resistance. Trans. Inst. Electr. Eng. Jpn. 1997, 117, 22-33. (In English) [CrossRef]

17. Yunus, S.; Nor, N.M.; Agbor, N.; Abdullah, S.; Ramar, K. Performance of Earthing Systems for Different Earth Electrode Configurations. IEEE Trans. Ind. Appl. 2015, 51, 5335-5342. [CrossRef]

18. Ramamoorty, M.; Narayanan, M.M.B.; Parameswaran, S.; Mukhedkar, D. Transient Performance of Grounding Grids. IEEE Trans. Power Deliv. 1989, 4, 2053-2059. [CrossRef]

19. Yang, S.; Zhou, W.; Huang, J.; Yu, J. Investigation on Impulse Characteristic of Full-Scale Grounding Grid in Substation. IEEE Trans. Electromagn. Compat. 2017, 60, 1993-2001. [CrossRef]

20. Clark, D.; Guo, D.; Lathi, D.; Harid, N.; Griffiths, H.; Ainsley, A.; Haddad, A. Controlled Large-Scale Tests of Practical Grounding Electrodes- Part II: Comparison of Analytical and Numerical Predictions with Experimental Results. IEEE Trans. Power Deliv. 2014, 29, 1240-1248. [CrossRef]

21. Harid, N.; Griffiths, H.; Haddad, A. Effect of Ground Return Path on Impulse Characteristics of Earth Electrodes. In Proceedings of the 7th Asia-Pacific International Conference on Lightning, Chengdu, China, 1-4 November 2011; pp. 686-689.

22. Abdullah, S.; Nor, N.M.; Etopi, N.; Reffin, M.; Othman, M. Influence of Remote Earth and Impulse Polarity on Earthing Systems by Field Measurements. IET Sci. Meas. Technol. 2017, 12, 308-313. [CrossRef]

23. Towne, H.M. Impulse Characteristics of Driven Grounds. Gen. Electr. Rev. 1928, 31, 605-609.

24. Vainer, A.L. Impulse Characteristics of Complex Earth Grids. Elektrichestvo 1965, 3, 107-117.

25. Vainer, A.L.; Floru, V.N. Experimental Study and Method of Calculating of the Impulse Characteristics of Deep Earthing. Electical Technol. Ussr (Gb) 1971, 2, 18-22.

26. Liew, A.C.; Darveniza, M. Dynamic Model of Impulse Characteristics of Concentrated Earths. IEE Proc. 1974, 121, 123-135. [CrossRef]

27. Chen, Y.; Chowdhuri, P. Correlation between Laboratory and Field Tests on the Impulse Impedance of Rod-type Ground Electrodes. IEE Proc. Gener. Transm. Distrib. 2003, 150, 420-426. [CrossRef]

28. Petropoulos, G.M. The High-Voltage Characteristics of Earth Resistances. J. IEE 1948, 95, 172-174.

(C) 2019 by the authors. Licensee MDPI, Basel, Switzerland. This article is an open access article distributed under the terms and conditions of the Creative Commons Attribution (CC BY) license (http:// creativecommons.org/licenses/by/4.0/). 